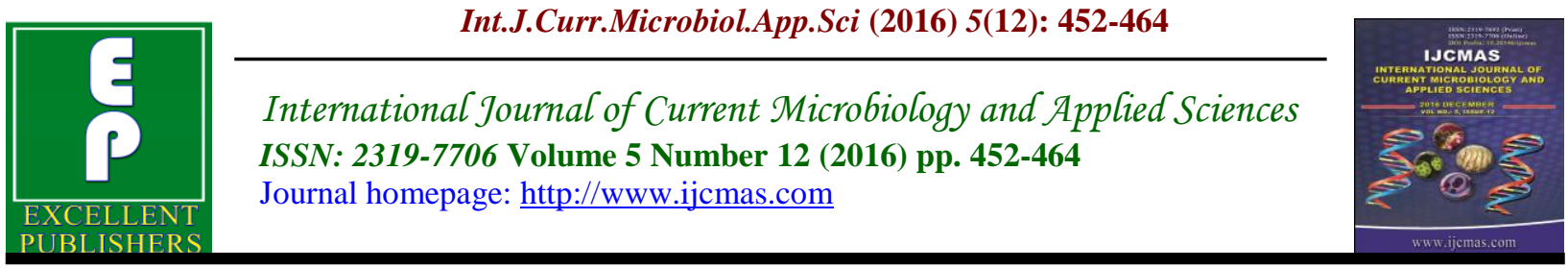

Original Research Article

http://dx.doi.org/10.20546/ijcmas.2016.512.049

\title{
Surveillance of Device-Associated Infection and Antimicrobial Resistance Rates in the Medical/Surgical Intensive Care Unit of Emergency Hospital at Tanta University, Egypt
}

\author{
Marwa M.E. Abd-Elmonsef ${ }^{1 *}$, Maii A. Shams Eldeen ${ }^{1}$, \\ Mohamed Samir Abd Elghafar ${ }^{2}$, A. Hagras ${ }^{3}$ and Walaa M. Shehata ${ }^{4}$ \\ ${ }^{1}$ Department of Microbiology and Immunology, Faculty of Medicine, Tanta University, Egypt \\ ${ }^{2}$ Department of Anesthesia and Surgical Intensive Care, Faculty of Medicine, \\ Tanta University, Egypt \\ ${ }^{3}$ Department of Urology, Faculty of Medicine, Tanta University, Egypt \\ ${ }^{4}$ Department of Public Health and Community Medicine, Faculty of Medicine, \\ Tanta University, Egypt \\ *Corresponding author
}

\section{Keywords \\ Device-associated infection; Intensive care unit; Antimicrobial resistance; Multi-drug resistance.}

\section{Article Info}

Accepted:

18 November 2016 Available Online: 10 December 2016

\section{A B S T R A C T}

To assess rates, bacteriological etiology and antimicrobial resistance patterns of the hospital acquired device-associated infection (DAI) in a medical/surgical intensive care unit (ICU). A prospective surveillance of DAI was conducted in the medical/surgical ICU, Emergency Hospital of Tanta University, Egypt, from 1st September 2015 to 1st March 2016, using the Centers for Disease Control and Prevention's National Healthcare Safety Network case criteria for the different DAIs. In this study, the overall rate of DAI was 24.17 per 1,000 device-days. Ventilator-associated pneumonia (VAP) was the most common DAI (52.17/1,000 ventilator-days), followed by catheter-associated urinary tract infection (CAUTI) (11.63 /1,000 catheter-days) and central line-associated blood stream infection (CLABSI) (6.93/1,000 central line-days). The main cause of VAP was Klebsiella pneumoniae, and for CAUTI, it was Escherichia coli. In CLABSI, methicillinsensitive Staphylococcus aureus and Staphylococcus epidermidis were equally presented. Overall, $92.68 \%$ of the isolated organisms in our study were multi-drug resistant. Gram-negative isolates showed highest resistance against the third generation cephalosporins ( $68.29 \%$ for each), followed by sulphamethoxazole / trimethoprime (63.41\%), and the least was against imipenem (12.2\%). Oxacillin resistance was $60 \%$ among the Gram-positive isolates. Routine microbiological surveillance are urgently needed to guide optimizing control measures and providing an obligating antimicrobial policy to prevent the high spread of multidrug resistant infections in ICUs.

\section{Introduction}

Health care-associated infection (HAI) has become a major threat to the safety of intensive care unit (ICU) patients. Currently, devices are the most important causes of HAI due to their prolonged use and lack of regular care or timely change when required 
(Jana et al., 2015). The most commonly reported device-associated infections (DAIs) involved central line-associated bloodstream infection (CLABSI), ventilator-associated pneumonia (VAP) and catheter-associated urinary tract infection (CAUTI) (Krein et al., 2015).

HAI is increasingly being caused by multidrug resistant (MDR) organisms, which are difficult to treat due to indiscriminate use of antimicrobials (Rosenthal, 2011). Development of antimicrobial resistance in bacteria prolongs hospitalization, increases morbidity and mortality rates, and results in excess economic cost (El-Saed et al., 2016). To reduce HAI, surveillance is an essential tool as it is the important first step of identifying problems and priorities in assuring patient safety. Conducting continuous prospective nationwide surveillance has helped to decrease infection rates in western countries. However, the effectiveness of continuous nationwide surveillance on HAI should be investigated in each country (Choi et al., 2015).

Most of the studies about DAI are carried out in developed countries where a systematic surveillance for HAI is routinely done, playing an important role in the infection control and quality assurance programs of hospitals (Edwards et al., 2009). In developing nations, HAI prevention programs are insufficiently funded by Governments. For this, it is essential to initiate systematic surveillance, based on standard definitions (Mathur et al., 2015). The Centers for Disease Control and Prevention (CDC)'s National Health Safety Network (NHSN) has established standardized criteria for ICU DA-HAI surveillance. This standardized surveillance method determines DAI rates per 1000 device-days, to be used as benchmarks among healthcare centers providing infection control practitioners (ICPs) with a deeper look at the challenges they are dealing with, so they can implement an effective plan to solve them (Horan et al., 2008).

This study was conducted in order to investigate the characteristics of DAI in reference to infection rates, pathogens most commonly associated with infection and their antibiogram pattern in one of the Egyptian ICUs.

\section{Patients and Methods}

\section{Setting}

A 6 months prospective surveillance was conducted in the medical/surgical ICU of Emergency Hospital, Tanta University during the period from $1^{\text {st }}$ September 2015 to $1^{\text {st }}$ March 2016. The unit provides inpatient care for critically ill adult patients. It consists of 3 wards, each contains 5 beds.

\section{Surveillance}

Standardized data were collected for all ICU patients with inserted devices, including demographic criteria (name, age, sex) and clinical criteria (date and indication of admission, date and indication of device insertion, signs of DAI, and the outcome). Daily data were collected on the following: the number of patients in the ICU and the total number of patient-days (bed-days), central line-days, mechanical ventilatordays, and urinary catheter-days. Patients on one or more devices were monitored to observe any infection related to the device use.

The infection control team consisted of 2 physicians, 2 microbiologists one of them was an ICP with 2 years of experience in infection control, and 2 link nurses. 
CDC/NHSN surveillance criteria were used to identify all specific types of HAI (CDC/NHSN Surveillance Definition, 2013).

\section{Sampling and microbiological study}

For VAP, a quantitative culture of aspirated endotracheal secretions was done, the growth was considered significant, if $>10^{5}$ colony forming units $(\mathrm{CFU}) / \mathrm{mL}$. For CAUTI, we used a quantitative culture of aseptically aspirated urine from the urinary catheter, the growth was considered significant, if $\geq 10^{3}$ and $<10^{5} \mathrm{CFU} / \mathrm{mL}$. For CLABSI, the distal 4-cm tip portion of the central venous catheter was cut and cultured after removing the catheter aseptically, with a concomitant percutaneously drawn blood culture. A cut-off of $\geq 15 \mathrm{CFU}$ for the tip culture is indicative of catheter colonization (CDC/NHSN Surveillance Definition, 2013). Concomitant blood samples for blood culture were per-cutaneously drawn to confirm central line-related blood stream infections.

Microbiological study was carried out in the laboratory of the Medical Microbiology and Immunology Department of Tanta Faculty of Medicine for identification of the isolated organisms by routine standard methods and the species was confirmed using the API 20E and API 20 NE systems (bioMerieux, France).

The antimicrobial susceptibility patterns were accessed by disc diffusion method and interpreted according to Clinical and Laboratory Standards Institute guidelines (Clinical and Laboratory Standards Institute, 2015). The following discs were used;

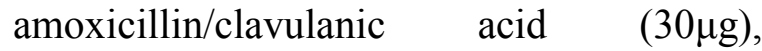
aztreonam $(30 \mu \mathrm{g}), \quad$ ceftriaxone $(30 \mu \mathrm{g})$, ceftazidime $(30 \mu \mathrm{g}), \quad$ cefoxitin $(30 \mu \mathrm{g})$, cefepime $(30 \mu \mathrm{g}), \quad$ ciprofloxacin $(5 \mu \mathrm{g})$, gentamicin $(10 \mu \mathrm{g})$, erythromycin $(15 \mu \mathrm{g})$, imipenem $(10 \mu \mathrm{g})$, linezolid $(30 \mu \mathrm{g})$, penicillin G (10 units), piperacillin/

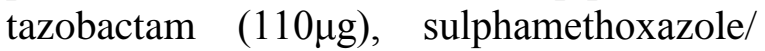
trimethoprim $(25 \mu \mathrm{g})$, tetracycline $(30 \mu \mathrm{g})$, vancomycin $(30 \mu \mathrm{g})$ [Oxoid, UK]. All isolates were screened for the production of extended-spectrum beta-lactamases (ESBL) and confirmed by double disc synergy test (Clinical and Laboratory Standards Institute, 2015).

\section{Calculation of DAI rates}

DAI rate was calculated by dividing the total number of DAIs (VAP, CAUTI or CLABSI) by device-days, multiplied by 1000 . Devicedays are the total number of days use for the relevant devices during the selected time period (Vallès et al., 2012). Device utilization ratio (DUR) was calculated by dividing the total number of device-days by the total number of patient-days (Dudeck $e t$ al., 2015). Patient-days are the total number of days that patients stay in the ICU during the selected time period (Apostolopoulou et al., 2013).

\section{Statistical analysis}

The results for quantitative variables were expressed as the mean $\pm \mathrm{SD}$ and were analyzed using Student's $t$ test. Qualitative variables were expressed as percentages and were compared using the z-test for proportions, while Fisher's exact test was used for small samples. A $P<0.05$ was considered statistically significant. All statistics were performed using Minitab17.

\section{Results and Discussion}

As far as we know, this is the first surveillance study that uses the definitions standardized by the CDC to estimate the rates of DAI and the associated 
antimicrobial resistance in Tanta University Hospitals. This surveillance was conducted in the medical/surgical ICU at Emergency Hospital of Tanta University, Egypt. Results of this study were analyzed in relation to the reports of another 2 Egyptian surveillances that followed the CDC criteria; one of them was carried out in a respiratory ICU of a member hospital of the INICC in Cairo (Raslan et al., 2012) and the other was carried out in the emergency ICU of Ain Shams University Hospital in Cairo (Hamdy et al., 2014). Also, our results were compared to the reports of 2 recent international studies conducted in medical/surgical ICUs of 2 developing countries, Malaysia (Rai et al., 2016) and Costa Rica (Ugalde et al., 2016). In addition, last international reports of INICC for the period (2007-2012) (Rosenthal et al., 2014) and CDC-NHSN (2013) (Dudeck et al., 2015) were used to compare our results. The lack of some data in these 6 comparable studies allowed only the comparison of the available data.

\section{Study population}

During the study period, surveillance data were prospectively collected for 105 patients admitted to the medical/ surgical ICU for a total of 855 patient-days. These patients were on one or more of invasive devices. Among them, only 28 (26.67\%) patients developed culture-confirmed DAIs, which were acquired during the study period.

Table 1 shows the demographic characteristics of the patients who acquired DAI (group I) compared to the patients without DAI. DAI was significantly associated with the two age extremes [below 20 years age $(P=0.02)$ and over 60 years age $(P<0.001)]$. There was no significant difference between the 2 groups regarding the sex distribution $(P=0.38)$. There were no significant differences between the 2 groups regarding the comorbid diseases except for ploytrauma with brain edema, which was significantly lower in patients with DAI $(P=0.03)$. The average length of ICU stay for patients with DAI was significantly higher than the other noninfected patients $(P<0.001)$. These results were in accordance with other studies (Talaat et al., 2010; Apostolopoulou et al., 2013). Also, the mortality rate was significantly higher in patients who acquired DAI than those without DAI $(P<0.001)$. Several reports confirmed that HAI increases the risk of death in critically ill patients (Bueno-Cavanillas et al., 1994; Ylipalosaari et al., 2006).

\section{DAI rates}

Table 2 shows the DAI rates, DURs, and the percentages of DAI distribution compared to the other 6 surveillances.

In this study, VAP represented the most frequent DAI (73.17\%), followed by CAUTI (19.51\%) and lastly CLABSI (7.32\%). This order was in accordance with those reported by both INICC report (2007-2012) (Dudeck et al., 2015) and Raslan et al., 2012 but with different percentages. Similarly, VAP was the most frequent DAI in both the Malaysian (Rai et al., 2016) and the Costa Rican (Ugalde et al., 2016) studies; however, CLABSI was more common than CAUTI in these studies. On the contrary, CAUTI was the main DAI detected by Hamdy et al., 2014. Interestingly, CLABSI was reported as the main DAI in another Egyptian study in a medical ICU (Abdelfattah et al., 2013). (Table 2)

DUR is used as an indicator for the severity of the disease because a patient with severe disease is more likely to use invasive devices for more days of his ICU stay 
(Dudeck et al., 2013). It can provide an evaluation of the population with intrinsic susceptibility to infection that have risk for DAI (Wright et al., 2011; Fakih et al., 2012). Therefore, DUR was used in this study to evaluate our DAI rates in relation to rates in the other studies. The overall rate of DAIs in the current study was $24.17 / 1,000$ device-days. It is higher than those reported by all our comparable studies, except that observed by Raslan et al., 2012 (52.9/1,000 device-days).

Our VAP rate was 52.17/1,000 ventilatordays which is higher than those reported by all our comparable studies (16.5 $48.12 / 1,000$ ventilator-days), except that observed by Raslan et al., 2012 (73.4/1,000 ventilator-days). This could be explained by the fact that mechanical ventilator use in our patients (0.67) was much higher than those reported by all other comparable studies (except for the Malaysian study, DUR = 0.74) (Rai et al., 2016). Our CAUTI rate was $11.63 / 1,000$ catheter-days with a DUR of 0.8. In comparison with other studies, it is close to that reported by Hamdy et al., 2014 $(12.74 / 1,000$ catheter-days, DUR $=0.73)$, but much lower than Raslan et al. 2012 (34.2/1,000 catheter-days, DUR =0.53); and much higher than all other comparable studies (1.27 - 5.34/1,000 catheter-days). As regards our CLABSI rate, it was 6.93/1000 central line-days. It was lower than those reported by both other Egyptian studies; (22.5/1000 central line-days) (Raslan et al., 2012)and (27.21/1000 central line-days) (Hamdy et al., 2014), but much higher than those reported by all other comparable studies (0.82 - 9.4/1000 central line-days). Our central line utilization ratio was 0.51 which was higher than the 2 Egyptian studies (0.35 and 0.12, respectively) (Raslan et al., 2012; Hamdy et al., 2014), and lower than other studies $(0.54-1.05)$; except for that reported by CDC-NHSN (2013) which was 0.37 (Dudeck et al., 2015).
This discrepancy in DAI rates could be explained according to 2 main factors; first one is the selection bias which includes the difference in the disease severity, type of the ICU, the duration and the time of the surveillance. The second factor is the availability of a well-established national infection surveillance system, which involves performance feedback programs, infection control fund, number of experienced ICPs, ratio of nurses to patients, and compliance with the guidelines of antimicrobial use.

\section{Bacterial profile of the detected DAIs}

The distribution of the isolated organisms from different DAIs through the study period is shown in table 3 .

In the current study, K. pneumoniae was the leading cause of DAI (43.9\%), followed by P. aeruginosa (17.07\%), and E. coli $(12.2 \%)$ (Table 3). This differed from that reported by Hamdy et al. 2014, where in their study; $S$. aureus was the predominant organism, followed by $E$. coli and $P$. aeruginosa ranked third. Also, the main isolated organisms from DAIs of the CDC-NHSN Report (2009-2010) were $S$. aureus, followed by E.coli and coagulase-negative S. aureus (CoNS) (Sievert et al., 2013). Unlike other studies (Aly et al., 2008; Apostolopoulou et al., 2013; Erdem et al., 2014), Acinetobacterbaumannii had low presentation in our ICU $(4.88 \%)$. This could be explained by the presumption that acquiring infection with A.baumannii depends on many risk factors; including the type of the underlying illness, its severity, the length of hospital stay, and the previous infection (Tilley and Roberts, 1994; Lortholary et al., 1995).

Notably, Gram-positive organisms accounted only for $(14.63 \%)$ in our study 
(Table 3). The high prevalence of Gramnegative organisms among ICU patients has been featured by several epidemiologic studies (Wisplinghoff et al., 2004; Vincent et al., 2009; Erdem et al., 2014). This finding could be explained by the presumption that oropharyngeal flora change into Gram-negative organisms after hospitalization (Johanson et al., 1969) and remain so for 3 months after discharge (Filius et al., 2005).

Considering the isolated organism according to the type of DAI, $K$. pneumoniae was the most frequent organism isolated from our VAP cases, followed by $P$. aeruginosa. While, E.coli, followed by Proteus mirabilis were the causative organisms of CAUTI in the present study. In our CLABSI, the causative organisms were methicillinsensitive $S$. aureus and $S$. epidermidis; they were equally presented. These results regarding the leading organism in each type of DAI agreed with those of Hamdy et al. 2014. On the contrary, our results differed from those presented by the CDC-NHSN Report (2009-2010) (Sievert et al., 2013); it denoted that $S$. aureus was the main organism causing VAP, and CoNS was the main in CLABSI. While, E. Coli was the leading cause of their CAUTI, which agreed with our results.

\section{Antimicrobial resistant pattern}

Overall in our Gram-negative isolates, the highest resistance was against the third generation cephalosporins (68.29\%), followed by

sulphamethoxazole/trimethoprime (63.41\%), and the least was against imipenem (12.2\%). While, oxacillin resistance was $60 \%$ among the Gram-positive isolates and no resistance was detected against neither vancomycin nor linezolid $(0 \%)$. In this study, Gram-negative organisms were defined as MDR, if resistant to 3 or more of the antimicrobial agents belonging to differed structural classes (Magiorakos et al., 2012). Also, MRSA is considered MDR (Garnacho-Montero et al., 2014). Accordingly, 92.68\% (38/41) of the isolated organisms in our study were MDR. This percentage is higher than that reported in a previous Egyptian study (55.36\%) (See et al., 2013), an Indian study (71.43\%) (Patel et al., 2016), and a Pakistani study (79.12\%) (Rizwan et al., 2016). ESBL were produced by $34.29 \%$ of our Gram-negative isolates (55.56\% of $\mathrm{K}$. pneumoniae and $40 \%$ of $E$. coli), which is higher than that reported by Hamdy et al., 2014 (23.47\%), but little lower than that reported by Saied et al., $2011(37.3 \%)$. There are several factors that can explain these higher resistance rates in our ICU, which include the strong association between colonization of MDR organisms and the length of patient hospitalization (Zhou et al., 2016). Also, the misuse of antimicrobials in our ICU in the form of unnecessary use of antimicrobials or their prescription without referring to the sensitivity report.

We preferred to compare our resistant rates with only the INICC report (2007-2012) (Rosenthal et al., 2014) and the CDC/NHSN report (2009-2010) (Sievert et al., 2013) to be more concise, since antimicrobial resistance data are lacking in the 2 comparable Egyptian studies (Table 4).

Our $P$. aeruginosa and $E$. coli isolates had the lowest resistant rates against quinolones (28.57\% and $20 \%$, respectively), versus $(41.9 \%$ and $70 \%$, respectively) reported by INICC (20072012) (Rosenthal et al., 2014) and (32.7\% and $29.1 \%$, respectively) reported by NHSN (2009-2010) (Sievert et al., 2013). Also, both isolates had the lowest resistance rates against carbapenems ( $0 \%$ for each); versus (42.8\% and $5.1 \%$, respectively) reported by INICC (2007-2012)(Rosenthal et al., 
2014) and $(30.2 \%$ and $1.7 \%$, respectively) reported by NHSN (20092010) (Sievert et al., 2013).

On the contrary, our $P$. aeruginosa isolates had the highest resistant rates against aminoglycosides and piperacillin/ tazobactam $\quad(71.42$ and $57.14 \%$, respectively); versus $(36.2 \%$ and $35.8 \%$, respectively) reported by INICC (20072012)(Rosenthal et al., 2014) and (11.3\% and $19.1 \%$, respectively) reported by NHSN (2009-2010) (Sievert et al., 2013). Also, We had the highest carbapenem-resistance rates in A. baumannii (100\%) versus $77.1 \%$ reported by INICC and $61.2 \%$ reported by NHSN.

Table.1 Demographic characteristics of the medical/surgical ICU patients during the study period

\begin{tabular}{|c|c|c|c|}
\hline Variant & $\begin{array}{c}\text { Patients } \\
\text { with DAI } \\
(\mathbf{n}=\mathbf{2 8})\end{array}$ & $\begin{array}{c}\text { Patients } \\
\text { without DAI } \\
(n=77)\end{array}$ & $P$ value \\
\hline \multicolumn{4}{|l|}{ Age $(y)$} \\
\hline$<20$ & $6(21.43)^{*}$ & $4(5.19)$ & 0.02 \\
\hline $20-40$ & $4(14.29)$ & $32(41.56)^{*}$ & 0.01 \\
\hline $40-60$ & $6(21.43)$ & $37(48.06) *$ & 0.01 \\
\hline$>60$ & $12(42.85)^{*}$ & $4(5.19)$ & $<0.001$ \\
\hline \multicolumn{4}{|l|}{ Sex } \\
\hline Male & $19(67.86)$ & $59(76.62)$ & \multirow[b]{2}{*}{0.38} \\
\hline Female & $9(32.14)$ & $18(23.38)$ & \\
\hline \multicolumn{4}{|l|}{ Cause of admission } \\
\hline Polytrauma with brain edema & $9(32.15)$ & $42(54.54) *$ & 0.03 \\
\hline Polytrauma with extra-dural hemorrhage & $5(17.86)$ & $15(19.48)$ & 0.85 \\
\hline Ventricular aneurism & $3(10.72)$ & $3(3.89)$ & 0.34 \\
\hline Uncontrolled diabetic ketoacidosis & $2(7.14)$ & $2(2.6)$ & 0.29 \\
\hline Intra-cerebral hemorrhage & $2(7.14)$ & 1(1.3) & 0.17 \\
\hline Degenerative brain diseases & $2(7.14)$ & $1(1.3)$ & 0.17 \\
\hline Pneumothorax & $1(3.57)$ & $4(5.19)$ & 1 \\
\hline Gastro-intestinal cancers & $1(3.57)$ & $7(9.1)$ & 0.68 \\
\hline Bladder cancer & $1(3.57)$ & 0 & 0.27 \\
\hline Hydrocephalus & $1(3.57)$ & $1(1.3)$ & 0.46 \\
\hline Thalamic contusion & $1(3.57)$ & 0 & 0.27 \\
\hline Status epilepticus & 0 & $1(1.3)$ & 1 \\
\hline \multicolumn{4}{|l|}{ Outcome } \\
\hline Died & $15(53.57)^{*}$ & $8(10.39)$ & $<0.001$ \\
\hline Average length of ICU stay & $13.5 \pm 1.7 *$ & $6.2 \pm 2.5$ & $<0.001$ \\
\hline
\end{tabular}

DAI; device-associated infection, ICU; intensive care unit. Data presented as n (\%)

* Statistically significant 
Table.2 Data and rates of DAI in this study in comparison with other reports

\begin{tabular}{|c|c|c|c|c|c|c|c|}
\hline DAI & $\begin{array}{l}\text { This } \\
\text { study }\end{array}$ & Egypt $^{1}$ & Egypt $^{2}$ & Malaysia $^{3}$ & $\begin{array}{l}\text { Costa } \\
\text { Rica } 4\end{array}$ & $\begin{array}{l}\text { INICC } \\
(2007- \\
2012)^{5}\end{array}$ & $\begin{array}{c}\text { CDC- } \\
\text { NHSN } \\
(2013)^{6}\end{array}$ \\
\hline \multicolumn{8}{|l|}{ VAP } \\
\hline $\begin{array}{l}\text { DAI } \\
\text { rate* }\end{array}$ & 52.17 & 73.4 & 48.12 & 21.2 & 30.7 & 16.5 & NA \\
\hline DUR & 0.67 & 0.37 & 0.16 & 0.74 & 0.29 & 0.36 & NA \\
\hline$\%$ of DAI & 73.17 & 50.97 & 37.5 & 52.83 & 78.26 & 49.77 & - \\
\hline \multicolumn{8}{|l|}{ CAUTI } \\
\hline $\begin{array}{l}\text { DAI } \\
\text { rate* }\end{array}$ & 11.63 & 34.2 & 12.74 & 5 & 1.5 & 5.34 & 1.27 \\
\hline DUR & 0.8 & 0.53 & 0.73 & 0.82 & 0.5 & 0.62 & 0.54 \\
\hline$\%$ of DAI & 19.51 & 34.19 & 45.83 & 13.84 & 6.52 & 27.69 & - \\
\hline \multicolumn{8}{|l|}{ CLABSI } \\
\hline $\begin{array}{l}\text { DAI } \\
\text { rate* }^{*}\end{array}$ & 6.93 & 22.5 & 27.21 & 9.4 & 2.9 & 4.93 & 0.82 \\
\hline DUR & 0.51 & 0.35 & 0.12 & 1.05 & 0.6 & 0.54 & 0.37 \\
\hline$\%$ of DAI & 7.32 & 14.84 & 16.67 & 33.33 & 15.22 & 22.54 & - \\
\hline \multicolumn{8}{|l|}{ Overall } \\
\hline $\begin{array}{l}\text { DAI } \\
\text { rate* }\end{array}$ & 24.17 & 52.9 & 20.05 & 11.38 & 8.19 & 7.83 & - \\
\hline DUR & 1.98 & 1.25 & 1.01 & 2.61 & 1.39 & 1.52 & - \\
\hline$\%$ of DAI & 100 & 100 & 100 & 100 & 100 & 100 & - \\
\hline $\begin{array}{l}\text { No of } \\
\text { DAI }\end{array}$ & 41 & 155 & 24 & 159 & 46 & 17736 & - \\
\hline $\begin{array}{l}\text { Type of } \\
\text { ICU }\end{array}$ & $\begin{array}{c}\text { adult } \\
\mathrm{m} / \mathrm{s}\end{array}$ & $\begin{array}{c}\text { adult } \\
\text { respiratory }\end{array}$ & $\begin{array}{c}\text { adult } \\
\text { emergency }\end{array}$ & $\begin{array}{c}\text { adult } \\
\mathrm{m} / \mathrm{s}\end{array}$ & $\begin{array}{c}\text { adult } \\
\mathrm{m} / \mathrm{s}\end{array}$ & $\begin{array}{c}\text { adult } \\
\mathrm{m} / \mathrm{s}\end{array}$ & $\begin{array}{c}\text { adult } \\
\mathrm{m} / \mathrm{s}\end{array}$ \\
\hline
\end{tabular}

1; Rasslan et al., 2012. 2; Hamdy et al., 2014. 3; Rai et al., 2016. 4; Ugalde et al., 2016. 5; Rosenthal et al., 2014. 6; Dudeck et al., 2015.

VAP; ventilator-associated pneumonia, CAUTI; catheter-associated urinary tract infection, CLABSI; central line-associated blood stream infection, DAI; device-associated infection, DUR; device utilization ratio, INICC; International Nosocomial Infection Control Consortium, CDCNHSN; Centers for Disease Control and National Healthcare Safety Network Data, NA; not available for adult rates, $\mathrm{m} / \mathrm{s}$; medical/surgical

Data presented as \%.*DAI rate was calculated per 1,000 device-days 
Table.3 Distribution of the isolated bacteria according to the type of DAI in this study

\begin{tabular}{|l|c|c|c|c|}
\hline \multicolumn{1}{|c|}{ Isolated organisms } & VAP & CAUTI & CLABSI & Total \\
\hline Klebsiella pneumoniae & 18 & - & - & 18 \\
\hline Pseudomonas aeruginosa & 7 & - & - & 7 \\
\hline MRSA & 3 & - & 1 & 4 \\
\hline Acinetobacter baumannii & 2 & - & - & 2 \\
\hline Escherichia coli & - & 5 & - & 5 \\
\hline Proteus mirabilis & - & 3 & - & 3 \\
\hline MSSA & - & - & 1 & 1 \\
\hline CoNS & - & - & 1 & 1
\end{tabular}

VAP; ventilator-associated pneumonia, CAUTI; catheter-associated urinary tract infection, CLABSI; central line-associated blood stream infection, MRSA; methicillin-resistant Staphylococcus aureus, MSSA; methicillin-sensitive Staphylococcus aureus. CoNS; coagulasenegative Staphylococcus aureus. Data presented as no.

Table.4 Antimicrobial resistance rates in this study in comparison with the INICC report (20072012) and the CDC-NHSN report (2009-2010)

\begin{tabular}{|c|c|c|c|c|c|}
\hline DAI & $\begin{array}{c}\text { Isolated } \\
\text { organism }\end{array}$ & Drug & This study & $\begin{array}{c}\text { INICC } \\
(2007-2012)^{1}\end{array}$ & $\begin{array}{l}\text { CDC-NHSN } \\
(2009-2010)^{2}\end{array}$ \\
\hline \multirow{8}{*}{ VAP } & $\begin{array}{l}\text { Staphylococcus } \\
\text { aureus }\end{array}$ & Oxacillin & 100 & 62 & 48.8 \\
\hline & \multirow{4}{*}{$\begin{array}{l}\text { Pseudomonas } \\
\text { aeruginosa }\end{array}$} & Carbapenems & 0 & 42.8 & 30.2 \\
\hline & & Aminoglycosides & 71.42 & 36.2 & 11.3 \\
\hline & & Fluoroquinolones & 28.57 & 41.9 & 32.7 \\
\hline & & Piperacillin/tazobactam & 57.14 & 35.8 & 19.1 \\
\hline & \multirow{2}{*}{$\begin{array}{l}\text { Klebsiella } \\
\text { pneumoniae }\end{array}$} & Carbapenems & 16.66 & 17.2 & 11.2 \\
\hline & & $\begin{array}{l}3^{\text {rd }} \text { generation } \\
\text { cephalosporins }\end{array}$ & 88.88 & 62.6 & 23.8 \\
\hline & $\begin{array}{l}\text { Acinetobacter } \\
\text { baumannii }\end{array}$ & Carbapenems & 100 & 77.1 & 61.2 \\
\hline \multirow{3}{*}{ CAUTI } & \multirow{3}{*}{$\begin{array}{l}\text { Escherichia } \\
\text { coli }\end{array}$} & Carbapenems & 0 & 5.1 & 1.7 \\
\hline & & $\begin{array}{l}3^{\text {rd }} \text { generation } \\
\text { cephalosporins }\end{array}$ & 60 & 63 & 11.5 \\
\hline & & Fluoroquinolones & 20 & 70 & 29.1 \\
\hline CLABSI & $\begin{array}{l}\text { Staphylococcus } \\
\text { aureus }\end{array}$ & Oxacillin & 50 & 61.2 & 51.5 \\
\hline
\end{tabular}

1; Rosenthal et al., 2014. 2; Sievert et al., 2013.

VAP; ventilator-associated pneumonia, CAUTI; catheter-associated urinary tract infection, CLABSI; central line-associated blood stream infection, DAI; device-associated infection, INICC; International Nosocomial Infection Control Consortium, CDC-NHSN; Centers for Disease Control and National Healthcare Safety Network Data, NA; not available for adult rates. Data presented as \%. 
As regards oxacillin, S. aureus isolated from our VAP cases had the highest resistance rate $(100 \%)$, compared to INICC (20072012) and NHSN (2009-2010) reports (62\% and $48.8 \%$, respectively) (Rosenthal et al., 2014; Sievert et al., 2013). While S. aureus isolated from our CLABSI cases had the lowest resistance rate $(50 \%)$ compared to INICC and NHSN reports $(61.2 \%$ and $51.5 \%$, respectively).

In conclusion, our surveillance revealed higher rates of DAI in our medical/surgical ICU in comparison with international reports, particularly VAP and CAUTI, but not CLABSI. These higher rates are quite similar to the other national surveillances. MDR rate in our ICU is higher than that reported by other developing countries. However, we still have lower resistance rates against both quinolones and carbapenems compared to INICC and NHSN reports. Actually, the small size of the samples in this study may affect the reliability of the results. Consequently, further studies including larger sample size for longer periods are necessary to clarify the magnitude of the DAI problem and developing more effective preventive measures.

\section{Competing interests}

Authors have declared that no competing interests exist.

\section{References}

Abdelfattah, M., Elkholy, A., Enany, M., Beheiry, I., and Saleh, D. 2013. P016: Device associated infections in adult intensive care units in public versus private hospitals in Egypt. Antimicrob. Resist. Infect. Control, 2(Suppl 1): P16.

Aly, N.Y.A., Al-Mousa, H.H., and Al Asar, M.E. 2008. Nosocomial Infections in a
Medical-Surgical Intensive Care Unit. Med. Princ. Pract., 17: 373-377.

Apostolopoulou, E., Raftopoulos, V., Filntisis, G., Kithreotis, P., Stefanidis, E. Galanis, P., and Veldekis, D. 2013. Surveillance of device-associated infection rates and mortality in 3 Greek intensive care units. Am. J. Crit. Care, 22(3): e12-20.

Bueno-Cavanillas, A., Delgado-Rodriguez, M., Lopez-Luque, A., Schaffino-Cano, S., and Galvez-Vargas, R. 1994. Influence of nosocomial infection on mortality rate in an intensive care unit. Crit. Care Med., 22: 55-60.

CDC/NHSN Surveillance Definition of Healthcare-Associated Infection and Criteria for Specific Types of Infections in the Acute Care Setting. 2013. Available at: https://www.cdph.ca.gov/programs/hai /Documents/Slide-Set-20-InfectionDefinitions-NHSN-2013.pdf

Choi, J.Y., Kwak, Y.J., Yooc, H., Lee, S. O., Kim, H.B., Han, S.H., Choi, H.J., Kim, Y.K., Kim, S.R., Kim, T.H., Lee, H., Chun, H.K., Kim, J.S., Eun, B.W., Kim, D.W., Koo, H.S., Bae, G.R., Lee, K., and Korean Nosocomial Infections Surveillance System (KONIS). 2015. Trends in the incidence rate of deviceassociated infections in intensive care units after the establishment of the Korean Nosocomial Infections Surveillance System. J. Hosp. Infect., 91(1): 28-34.

Clinical and Laboratory Standards Institute (CLSI 2015). Performance Standards for Antimicrobial Susceptibility Testing. $\quad 25^{\text {th }} \quad$ informational supplement, CLSI document M100S25. Wayne, PA: CLASI; 2015.

Dudeck, M.A., Weiner, L.M., Allen-Bridson, K., Malpiedi, P.J., Peterson, K.D., Pollock, D.A., Sievert, D.M., and Edwards, J.R. 2013. National Healthcare Safety Network (NHSN) report, data summary for 2012, 
Device-associated module. Am. $J$. Infect. Control, 41(12): 1148-1166.

Dudeck, M.A., Edwards, J.R., Allen-Bridson, K., Gross, C., Malpiedi, P.J., Peterson, K. D., Pollock, D. A., Weiner, L. M., and Sievert, D. M. 2015. National Healthcare Safety Network report, data summary for 2013, Device-associated Module. Am. J. Infect. Control, 43(3): 206-221.

Edwards, J.R., Peterson, K.D., $\mathrm{Mu}, \mathrm{Y}$, Banerjee, S., Allen-Bridson, K., Morrell, G., Dudeck, M.A., Pollock, D.A., and Horan, T.C. 2009. National Healthcare Safety Network (NHSN) report: data summary for 2006 through 2008, issued December 2009. American J. Infect. Control, 37: 783805.

El-Saed, A., Al-Jardani, A., Althaqafi, A., Alansari, H., Alsalman, J., Al Maskari, Z., El Gammal, A., Al Nasser, W., AlAbri, S.S., and Balkhy, H.H. 2016. Ventilator-associated pneumonia rates in critical care units in 3 Arabian Gulf countries: A 6-year surveillance study. AJIC, 44(7): 794-798.

Erdem, H., Inan, A., Altındis, S., Carevic, B., Askarian, M., Cottle, L., et al. 2014. Surveillance, control and management of infections in intensive care units in Southern Europe, Turkey and Iran. A prospective multicenter point prevalence study. J. Infect., 68(2): 131-140.

Fakih, M.G., Greene, M.T., Kennedy, E.H., Meddings, J.A., Krein, S.L., Olmsted, R.N., and Saint, S. 2012. Introducing a population-based outcome measure to evaluate the effect of interventions to reduce catheter-associated urinary tract infection. Am. J. Infect. Control, 40: 359-364.

Filius, P.M.G., Gyssens, I.C., Kershof, I.M., Roovers, P.J.E., Ott, A., Vulto, A.G., Verbrugh, H.A., and Endtz, H.P. 2005. Colonization and Resistance Dynamics of Gram-Negative Bacteria in Patients during and after Hospitalization.
Antimicrob Agents Chemother., 49(7): 2879-2886.

Garnacho-Montero, J., Corcia-Palomo, Y., Amaya-Villar, R., and Martin-Villen, L. 2014. How to treat VAP due to MDR pathogens in ICU patients. BMC Infect Dis., 14: 135-141.

Hamdy, M. S., Shabban, M., Mohamed, A. K., and Abdallah, N. G.2014. DeviceAssociated Infections and Antimicrobial Resistance Patterns of Isolated Pathogens in Surgical Intensive Care Unit at Ain Sham University Hospital. EJMM, 23(4): 1726.

Horan, T. C., Andrus, M., and Dudeck, M. A. 2008. CDC/NHSN surveillance definition of health care-associated infection and criteria for specific types of infections in the acute care setting. American J. Infection Control, 36:309332.

Jana, A., Majumdar, A., Mitra, J., Biswas, S. and Bag, B. 2015. Device-associated infection rates and median length of acquiring device-associated infection in an intensive therapeutic unit of an Indian hospital. J. Med. Trop., 17(2):97-102.

Johanson, W. G., Pierce, A. K., and Sanford, J. P. 1969. Changing Pharyngeal Bacterial Flora of Hospitalized Patients, Emergence of Gram-Negative Bacilli. N. Engl. J. Med., 281: 11371140.

Krein, S.L., Fowler, K.E., Ratz, D., Meddings, J., and Saint, S. 2015. Preventing device-associated infections in US hospitals: national surveys from 2005 to 2013. BMJ Qual. Saf., 24(6): 385392.

Lortholary, O., Fagon, J. Y., Hoi, A. B., Slama, M. A., Pierre, J., Giral, P., Rosenzweig, R., Gutmann, L., Safar, M., and Acar, J. 1995. Nosocomial Acquisition of Multiresistant Acinetobacter baumannii: Risk Factors and Prognosis. Clin. Infect. Dis., 20(4): 790-796. 
Magiorakos, A. P., Srinivasan, A., Carey, R. B., Carmeli, Y., Falagas, M. E., Giske, C. G., Harbarth, S., Hindler, J. F., Kahlmeter, G., Olsson-Liljequist, B., Paterson, D. L., Rice, L. B., Stelling, J., Struelens, M. J., Vatopoulos, A., Weber, J. T., and Monnet, D. L. 2012. Multidrug-resistant, extensively drugresistant and pandrug-resistant bacteria: an international expert proposal for interim standard definitions for acquired resistance. CMI, 18(3): 268-281.

Mathur, P., Tak, V., Gunjiyal, J., Nair, S. A., Lalwani, S., Kumar, S., Gupta, B., Sinha, S., Gupta, A., Gupta, D., and Misra, M. C. 2015. Device-associated infections at a level-1 trauma centre of a developing Nation: Impact of automated surveillance, training and feedbacks. Indian J. Med. Microbiol., 33: 51-62.

Patel, B.V., Panchal, P., Patel, D., and Vegad, M. M. 2016. A Study of Bacteriological Profile And Their Antibiotic Susceptibility Patterns Of Isolated Organisms From ICU's With Special Reference To Multi-Drug Resistant Organisms. NJIRM, 7(3):2529.

Rai, V., Yuet-Meng, C., Rosenthal, V. D., Hasan, M. S., Zaman, M. K., Mansor, M., et al.2016. Device-associated infection and mortality rates, bacterial resistance, and length of stay in hospitals of Malaysia: International Nosocomial Infection Control Consortium (INICC)'s findings. Can. J. Infect. Control, 31(2):107-112.

Rasslan, O., Seliem, Z., Ghazi, I., Abd El Sabour, M., El Kholy, A., Sadeq, F. M., Kalil, M.,Abdel-Aziz, D., Sharaf, H. Y., Saeed, A., Agha, H., Zein ElAbdeen, S. A., El Gafarey, M., El Tantawy, A., Fouad, L., Abel-Haleim, M. M., Muhamed, T., Saeed, H., and Rosenthal, V. D. 2012. Deviceassociated infection rates in adult and pediatric intensive care units of hospitals in Egypt. International Nosocomial Infection Control Consortium (INICC) findings. $J$. Infect. Public Health, 5: 394-402.

Rizwan, M., Ikram, A., Zaman, G., Satti, L., and Ahmed, P. 2016. Surveillance of device-associated infections in intensive care units of a tertiary care hospital. J. Hosp. Infect., Available online: 20 October 2016. In Press.

Rosenthal, V.D. 2011. Health-care associated infections in developing countries. Lancet, 377:186-188.

Rosenthal, V. D., Maki, D. G., Mehta, Y., Leblebicioglu, H., Memish, Z. A., AlMousa, H. H., et al.2014. International Nosocomial Infection Control Consortium (INICC) report, data summary of 43 countries for 20072012. Device-associated module. Am. J. Infect Control, 42(9):942-956.

Saied, T., Elkholy, A., Hafez, S. F., Basim, H., Wasfy, M. O., El-Shoubary, W., Samir, A., Pimentel, G., Talaat, M.2011. Antimicrobial resistance in pathogens causing nosocomial bloodstream infections in university hospitals in Egypt. Am. J. Infect. Control, 39: e61-65.

See, I., Lessa, F.C., Abo ElAta, O., Hafez, S., Samy, K., El-Kholy, A., El Anani, M. G., Ismail, G., Kandeel, A., Galal, R., Ellingson, K., and Talaat, M. 2013. Incidence and Pathogen Distribution of Healthcare-Associated Infections in Pilot Hospitals in Egypt. Infect Control Hosp. Epidemiol., 34(12): 1281-1288.

Sievert, D.M., Ricks, P., Edwards, J.R., Schneider, A., Patel, J., Srnivasan, A., Kallen, A., Limbago, B., Fridkin, S., and for the National Healthcare Safety Network (NHSN) Team and Participating NHSN Facilities. 2013. Antimicrobial-Resistant Pathogens Associated with Healthcare-Associated Infections: Summary of Data Reported to the National Healthcare Safety Network at the Centers for Disease Control and Prevention, 2009-2010. 
Infect Control Hosp. Epidemiol., 34(1): 1-14.

Talaat, M., Hafez, S., Saied, T., Elfeky, R., ElShoubary, W., and Pimentel, G. 2010. Surveillance of catheter-associated urinary tract infection in 4 intensive care units at Alexandria university hospitals in Egypt. Am. J. Infect Control, 38(3): 222-228.

Tilley, P.A.G and Roberts, F.J. 1994. Bacteremia with Acinetobacter Species: Risk Factors and Prognosis in Different Clinical Settings. Clin. Infect. Dis., 18(6): 896-900.

Ugalde, O.C., Hidalgo, R.F., Rosenthal, V. D., Hernandez, I. C., Gutierrez, G. M., Fuentes, C. G, Vargas, L. M., Chinchilla, A.S., Chavarría, M. A. Z., and Ruiz, A.A. 2016. Deviceassociated infection rates, bacterial resistance, length of stay, and mortality in intensive care units of Costa Rica: Findings of the International Nosocomial Infection Control Consortium (INICC). Can. J. Infect. Control, 31(1): 28-34.

Vallès, J., Limón, E., Díaz, E., Fernández, I., Palomar, M., Barcenilla, F., ÁlvarezLermag, F., and Pujolh, M., on behalf of VINCat Program. 2012. Deviceassociated infection rates in Adult Intensive Care Units in Catalonia: VINCat Program findings. Enferm Infect. Microbiol. Clin., 30(Supl 3): 33-38.
Vincent, J.L., Rello, J., Marshall, J., Silva, E., Anzueto, A., Martin, C. D., Moreno, R., Lipman, J., Gomersall, C., Sakr, Y., Reinhart, K., and EPIC II Group of Investigators. 2009. International study of the prevalence and outcomes of infection in intensive care units. JAMA, 302: 2323-2329.

Wisplinghoff, H., Bischoff, T., Tallent, S. M., Seifert, H., Wenzel, R. P., and Edmond, M. B. 2004. Nosocomial bloodstream infections in US hospitals: analysis of 24,179 cases from a prospective nationwide surveillance study. Clin. Infect. Dis., 39: 309-317.

Wright, M.O., Kharasch, M., Beaumont, J. L., Peterson, L.R., and Robicsek, A. 2011. Reporting catheter-associated urinary tract infections: denominator matters. Infect Control Hosp. Epidemiol., 32: 635-640.

Ylipalosaari, P., Ala-Kokko, T.I., Laurila, J., Ohtonen, P., and Syrjälä1, H. 2006. Intensive care acquired infection is an independent risk factor for hospital mortality: a prospective cohort study. Crit. Care, 10: R66.

Zhou, P., Xiong, X., Li, C., and Wu, A. 2016. Association of Length of Stay With Contamination of Multidrug-Resistant Organisms in the Environment and Colonization in the Rectum of Intensive Care Unit Patients in China. Infect. Control Hosp. Epidemiol., 37(1): 120-121.

\section{How to cite this article:}

Marwa M.E. Abd-Elmonsef, Maii A. Shams Eldeen, Mohamed Samir Abd Elghafar, A. Hagras and Walaa M. Shehata. 2016. Surveillance of Device-Associated Infection and Antimicrobial Resistance Rates in the Medical/Surgical Intensive Care Unit of Emergency Hospital at Tanta University, Egypt. Int.J.Curr.Microbiol.App.Sci. 5(12): 452-464. doi: http://dx.doi.org/10.20546/ijcmas.2016.512.049 